\title{
Assessment of Quasi-Static and Fatigue Loaded Notched GRP Laminates Using Digital Image Correlation
}

\author{
W. R. Broughton ${ }^{1, a}$, M. R. L. Gower, b, M. J. Lodeiro ${ }^{1, c}$, G. D. Pilkington ${ }^{1, d}$ \\ and R. M. Shaw ${ }^{1, e}$ \\ ${ }^{1}$ Materials Division, National Physical Laboratory, Teddington, Middlesex, TW11 OLW, UK \\ abill.broughton@npl.co.uk, ’michael.gower@npl.co.uk, maria.lodeiro@npl.co.uk, \\ 'gordon.pilkington.@npl.co.uk, richard.shaw@npl.co.uk
}

Keywords: Digital image correlation (DIC), fatigue, glass fibre-reinforced plastics (GRP), mechanical properties, strain measurement

\begin{abstract}
This paper presents the results of an experimental study carried out to assess the effects of cumulative damage on the strain response of open-hole (notched) quasi-isotropic [45/0/-45/90 $]_{4 \mathrm{~s}}$ Eglass/913 epoxy laminate specimens under quasi-static tension, and constant amplitude tensiontension, compression-compression and tension-compression cyclic loading conditions. In-plane surface strain was measured as a function of applied load and loading cycles for quasi-static and cyclic loading respectively using digital image correlation (DIC) and compared with strain gauge, fibre Bragg grating (FBG) optical sensor and contact extensometer strain measurements. DIC proved successful in monitoring local (near the hole) and global strains, providing critical information on the changes in strain distribution resulting from damage formation and growth incurred.
\end{abstract}

\section{Introduction}

The measurement of displacements and displacement gradients (i.e. strains) is now recognised as an important field of experimental stress analysis. Optical techniques, such as moiré interferometry, holographic interferometry and electronic speckle pattern interferometry (ESPI) are well established and used extensively for research and field inspection. However, these techniques have inherent sensitivity and resolution limitations along with issues relating to system stability and processing of fringe patterns, although computational algorithms for processing the data have been developed. An alternative approach is to use digital image correlation (DIC), which enables the operator to directly compare high quality images of the component to measure deformation rather than having to analyze complex fringe patterns. The technique has been successfully applied to both isotropic and anisotropic materials to study strain deformation, residual stress (e.g. hole drilling) and damage formation (e.g. crack growth) [1-3]. The work presented in this study uses DIC for measuring surface deformation under quasi-static and constant amplitude cyclic loading conditions. The results are compared with strain gauge, fibre Bragg grating (FBG) optical sensor and contact extensometer strain measurements.

\section{Material and Experimental Procedure}

Quasi-static and constant amplitude (sinusoidal waveform) cyclic fatigue tests were carried out on open-hole tension (OHT) and open-hole compression (OHC) coupon specimens machined from quasi-isotropic [45/0/-45/90] $]_{4 s}$. E-glass/913 epoxy laminates. The laminates $(600 \mathrm{~mm}$ x $300 \mathrm{~mm})$ were autoclave manufactured at the National Physical Laboratory using pre-impregnated tapes ( $0.125 \mathrm{~mm}$ thick) supplied by Hexcel Composites Ltd. The cure cycle was in accordance with the supplier's specifications. The fibre volume fraction of the laminates, as measured using the burn-off technique specified in ISO 1172 "Textile-glass-reinforced plastics - Prepregs, moulding compounds 
and laminates - Determination of the textile-glass and mineral-filler content - Calcination methods", was $54.0 \pm 0.2 \%$. OHT specimens were $250 \mathrm{~mm}$ in length, $36 \mathrm{~mm}$ wide and nominally $4 \mathrm{~mm}$ (32 ply) thick with a centrally located $6 \mathrm{~mm}$ diameter hole (Fig. 1). OHC specimens are a shorter version of the OHT specimen (i.e. $125 \mathrm{~mm}$ long with a $25 \mathrm{~mm}$ gauge-section) - see Fig. 2. The specimens were gripped via end tabs $(50 \mathrm{~mm}$ long) manufactured from a plain-woven glass fabric/epoxy laminate (1.6 mm thick), with the fibre axes of the fabric set at $\pm 45^{\circ}$ to the specimen axis, and adhesively bonded to the specimen. The tab angle is $90^{\circ}$ (i.e. not tapered). Specimen geometry and loading arrangement was in accordance with ASTM D 5766 D "Standard test method for open-hole tensile strength of polymer matrix composite laminates" and ISO/WD 12817 "Carbon-fibre-reinforced composites - Determination of open-hole compressive strength".

OHT tensile tests (Fig. 3) and OHC cyclic fatigue tests were conducted using an Instron 5500 servo-hydraulic test machine with the load introduced via fatigue-rated hydraulic wedge-action grips. A test frequency of $5 \mathrm{~Hz}$ was used for the fatigue tests. A lateral grip pressure of $200 \mathrm{bar}$ was applied. Instron MAX software was used to control the test machine, and for data capture. The OHC strength was obtained by loading the specimens via end-loading blocks between two parallel, hardened stainless steel platens within a four-post die set to minimise buckling (Fig. 4). Testing was carried out under standard laboratory conditions $\left(23 \pm 2{ }^{\circ} \mathrm{C}, 50 \pm 10 \%\right.$ relative humidity).

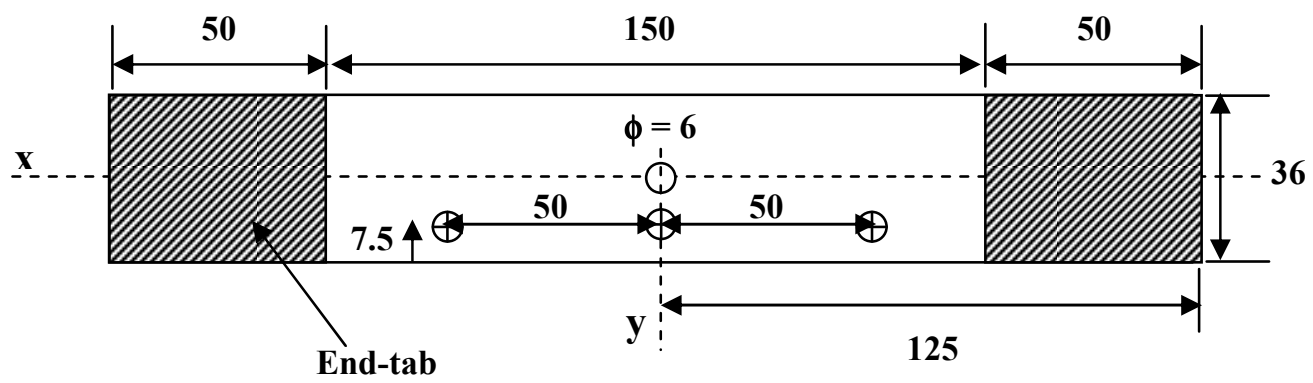

Figure 1. Open-hole (notched) tension specimen (units: $\mathrm{mm}$ )

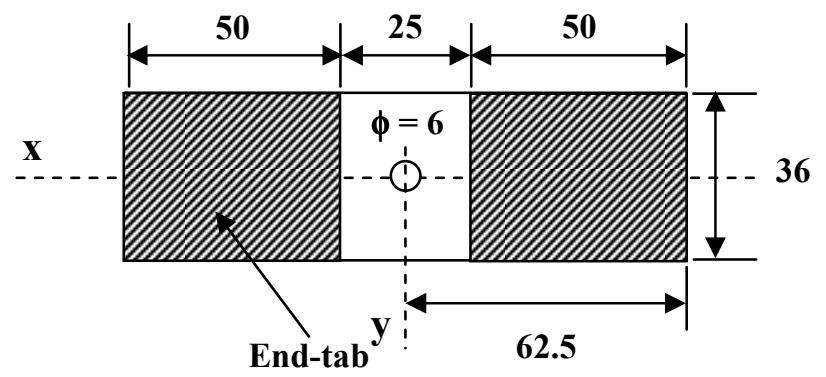

Figure 2. Open-hole (notched) compression specimen (units: mm)
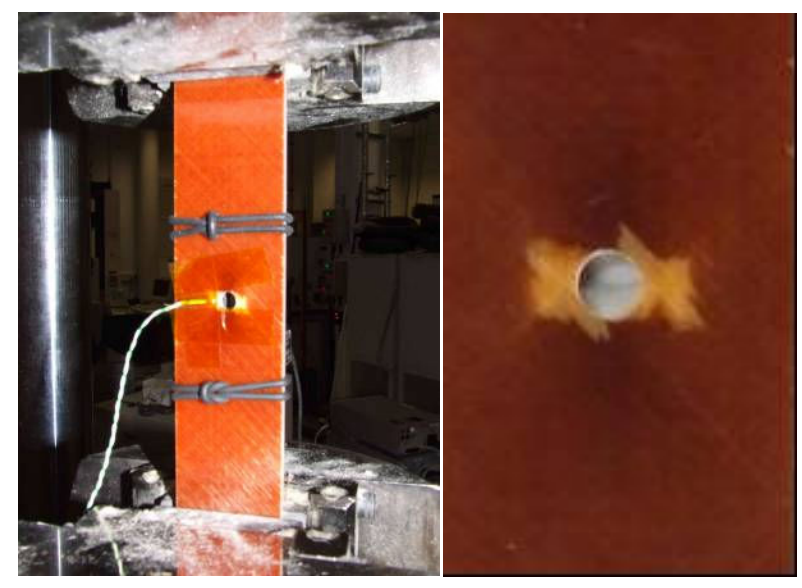

Figure 3. Open-hole tension test

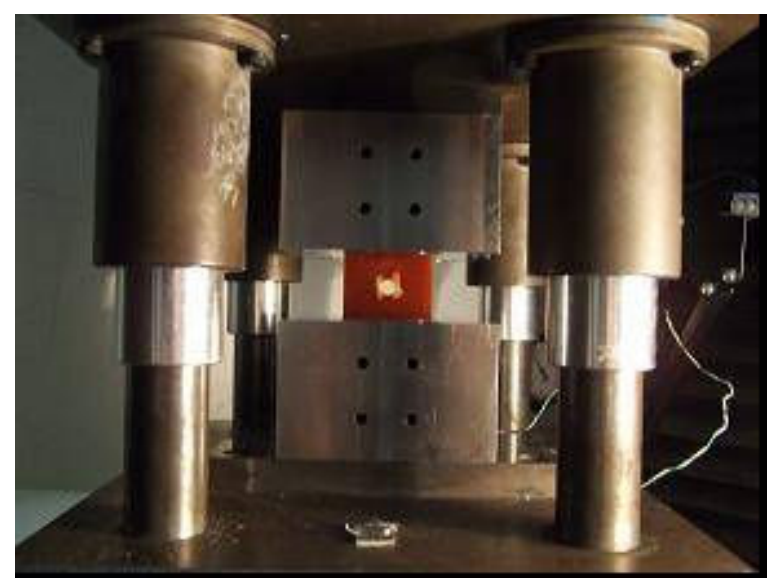

Figure 4. Open-hole compression test 
In-plane strain was measured using DIC, strain gauges adhesively bonded to the specimen surface, fibre Bragg grating (FBG) optical sensors embedded in the laminate and a contact (clipgauge) extensometer with a gauge-length of $50 \mathrm{~mm}$ located at the mid-section of the specimen (see Fig. 3). DIC was the only strain measurement technique used for monitoring strain distributions in the $\mathrm{OHC}$ tests. A LaVision ${ }^{\circledR}$ DIC system with a single megapixel $(1280 \times 1024$ pixel $)$ video camera was used to obtain two dimensional (2D) maps of the strain distributions $\left(\varepsilon_{\mathrm{xx}}, \varepsilon_{\mathrm{yy}}\right.$ and $\left.\varepsilon_{\mathrm{xy}}\right)$ along the length and across the width of notched specimens that had been subjected to either quasi-static or fatigue loading. One face of the coupon specimens was sprayed with black, grey and white paint to produce a specular random pattern for the image correlation. Images were recorded at a frequency of $1 \mathrm{~Hz}$ throughout the tests and all strain results were calculated relative to the first image recorded at zero load. LaVision ${ }^{\circledR}$ Strainmaster software was used for data capture and analysis (conversion of displacement to strain). For quasi-static testing, the load was increased in incremental steps at a displacement rate of $1 \mathrm{~mm} / \mathrm{min}$ and the resultant displacement field was measured. This was repeated until an applied load was reached beyond which the damage in the vicinity of the hole was too extensive to obtain sensible strain measurements. In the case of fatigue testing, the test was stopped at set intervals of 10,000 cycles, and the resultant strain field was measured at a constant static load equivalent to the maximum load level of the fatigue cycle. The normal and shear strain distributions were determined along the central axes in the $\mathrm{x}$ - (loading) and $\mathrm{y}$ - (tranverse) directions of the notched specimens as a function of applied load or loading cycles.

\section{Quasi-Static Tensile Tests}

The un-notched and notched laminate tensile strength, measured at an equivalent displacement rate as the fatigue tests (i.e. $500 \mathrm{~mm} / \mathrm{min}$ ), was $484 \pm 18 \mathrm{MPa}$ and $346 \pm 5 \mathrm{MPa}$, respectively. The corresponding tensile modulus, measured using the contact extensometer, was $21.9 \pm 0.4 \mathrm{GPa}$ and $20.6 \pm 0.3 \mathrm{GPa}$. Each set of results represents five tests. The contact extensometer was only used to measure strain at low levels $(0.05-0.25 \%)$ as the violent nature of the failure that occurs could have damaged the device. Strain in the OHT specimen was also measured using strain gauges located $7.5 \mathrm{~mm}$ in from the specimen edge at the centre-line, and at locations $50 \mathrm{~mm}$ above and 50 $\mathrm{mm}$ below the centre-line (see Fig. 1). The corresponding tensile modulus and failure strains obtained were $20.2 \mathrm{GPa}, 19.9 \mathrm{GPa}$ and $21.9 \mathrm{GPa}$, and $3.12 \%, 2.14 \%$ and $2.01 \%$, respectively. The strain gauges located $50 \mathrm{~mm}$ from the centre-line are in low strain regions. The higher failure strain value obtained at the centre-line was due to a loss of stiffness resulting from localized damage near the hole (see Fig. 3). The strains measured using the different techniques were in good agreement as shown in Fig. 5. The strains tend to diverge at higher loads due to damage growth around the hole.

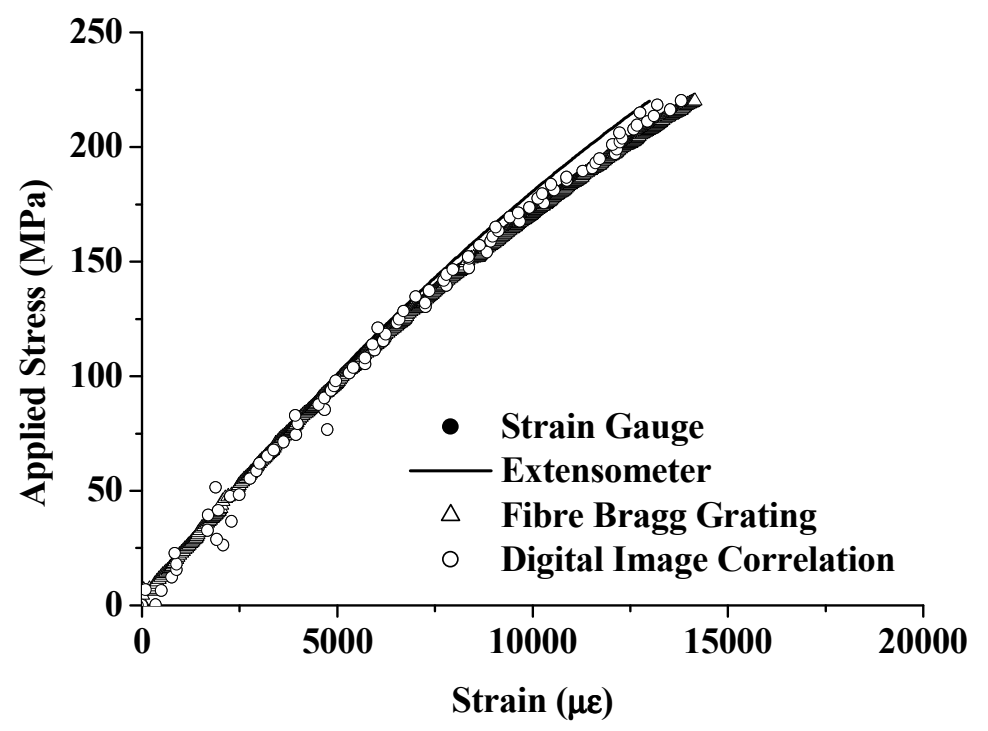

Figure 5. Comparison of OHT centre-line strain measurements for the four different techniques 
Failure involves a number of fracture mechanisms commencing with matrix cracking of the $90^{\circ}$ plies occurring near the hole boundary at an applied stress of $\sim 60 \mathrm{MPa}$ (coinciding with nonlinearity of the axial stress/strain response) followed by matrix cracking of the $\pm 45^{\circ}$ plies (surface cracking occurs at $\sim 243 \mathrm{MPa}$ ); splitting in the $0^{\circ}$ plies and local delaminations at the interfaces between the $45^{\circ}$ and $90^{\circ}$ plies; and finally by fibre fracture and pull-out. Fig. 6 shows the $\varepsilon_{\mathrm{xx}}$ strain distribution across the specimen width as a function of increasing applied load measured using DIC. It can be seen that the distribution is not symmetrical about the hole due to the non-uniformity of damage formation (see Fig. 3). Fig. 7 compares the average value of strain concentrations $\varepsilon_{\mathrm{xx}} / \varepsilon^{\infty} \mathrm{xx}$ (where $\varepsilon_{\mathrm{xx}}$ and $\varepsilon_{\mathrm{xx}}^{\infty}$ denote local strain and applied strain) measured from the edge of the hole to the edge of the specimen at 50\%, 60\% and 67\% UTS (ultimate tensile strength) with the analytical solution predictions for an orthotropic plate with a circular hole [4]. Again, the results are in reasonable agreement. The effects of damage become more apparent as the load increases. Beyond a stress level of approximately $233 \mathrm{MPa}$ (67\% UTS) damage became too extensive to be able to reliably measure displacement gradients near the hole using DIC.

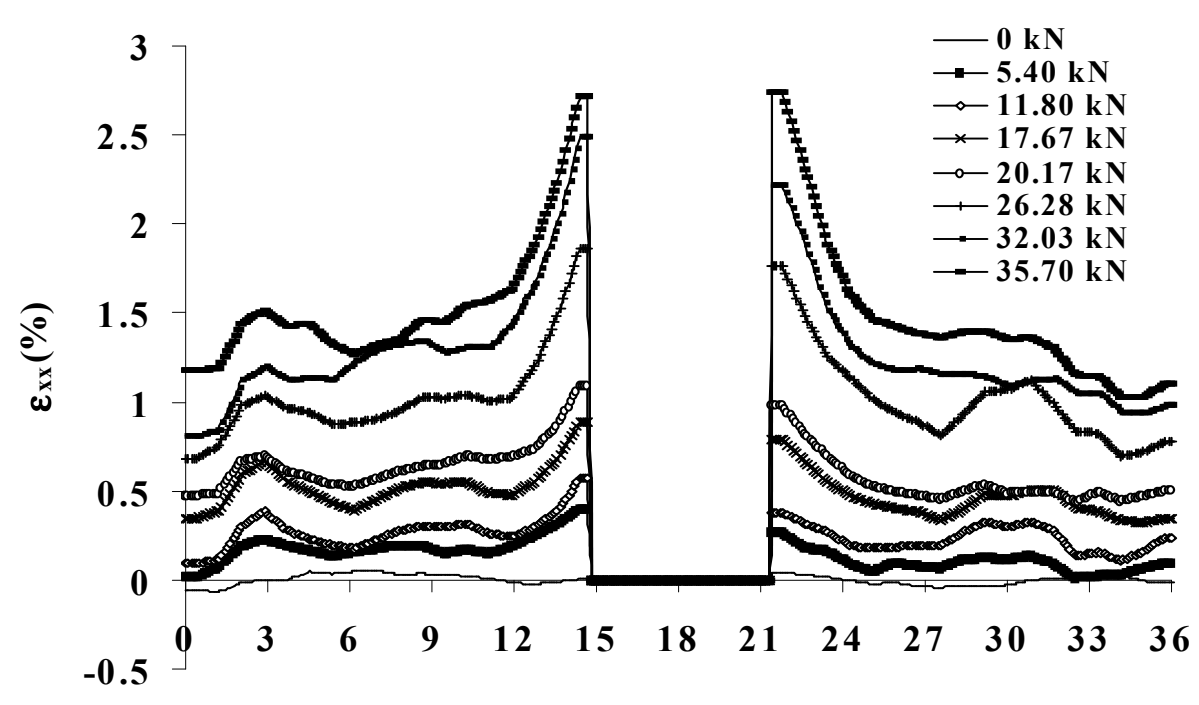

Distance across specimen width $(\mathrm{mm})$

Figure 6. $\varepsilon_{\mathrm{xx}}$ strain distribution around the hole as a function of applied load

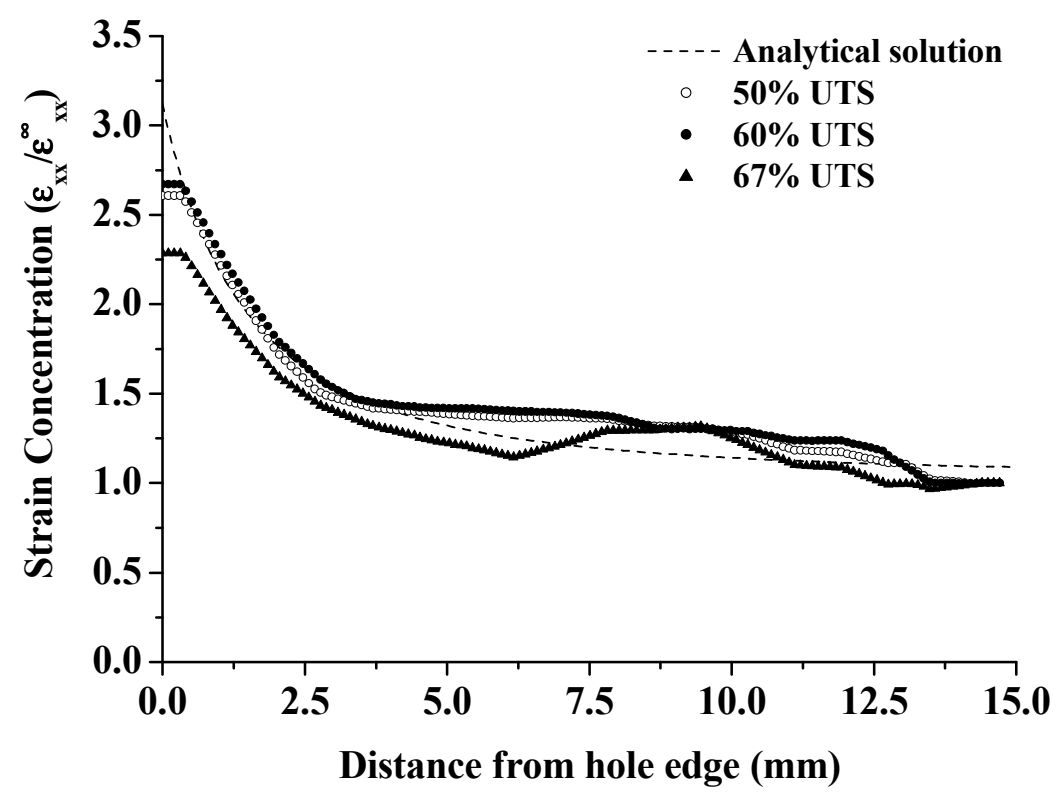

Figure 7. Strain concentration $\varepsilon_{\mathrm{xx}} / \varepsilon^{\infty}{ }_{\mathrm{xx}}$ across the centre-line of the specimen 


\section{Cyclic Fatigue Tests}

The ability to monitor damage growth using DIC becomes apparent when examining the fatigue behaviour of OHT and OHC specimens. OHT specimens were subjected to constant amplitude tension-tension (T-T) and the OHC specimens to either compression-compression (C-C) or tensioncompression (T-C) cyclic loading conditions. The stress ratio $R\left(\sigma_{\min } / \sigma_{\max }\right)$ values, and maximum applied stresses for the three loading conditions were $0.1,10$ and -1 , and $156 \mathrm{MPa},-215 \mathrm{MPa}$ and $123 \mathrm{MPa}$. The tests were stopped at set intervals of 10,000 cycles, unloaded and then statically reloaded to a constant load to enable DIC imaging of the specimen surface. The static load applied for imaging was $20 \mathrm{kN}(133 \mathrm{MPa})$ for T-T, $-25 \mathrm{kN}(-164 \mathrm{MPa})$ for C-C and 15kN (100 MPa) for T-C. Strain maps of $\varepsilon_{\mathrm{xx}}$ as a function of loading cycles for the three fatigue cases are shown in Fig. 8.

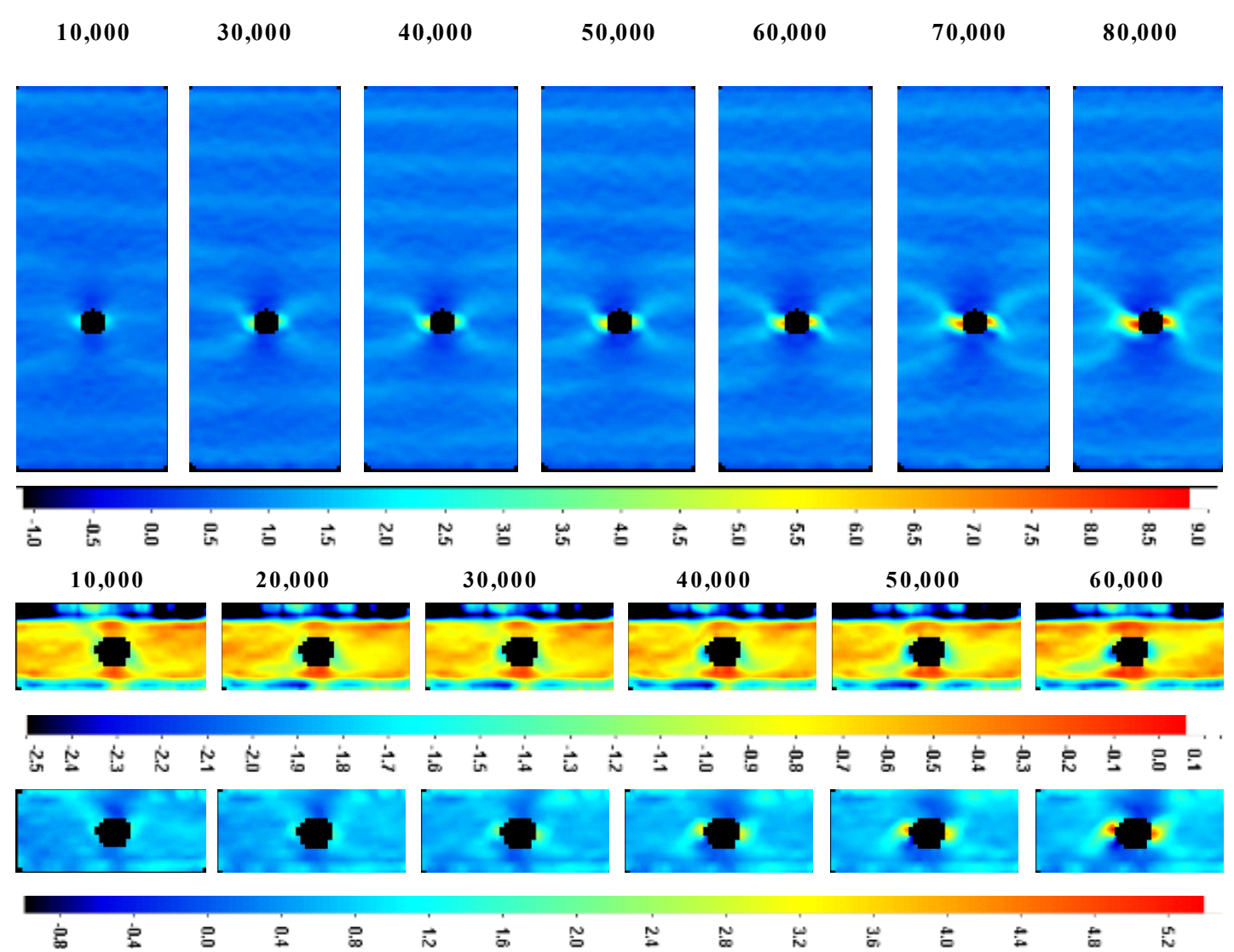

Figure 8. $\varepsilon_{\mathrm{xx}}$ strain distribution versus loading cycles: T-T (top), C-C (middle) and T-C (bottom)

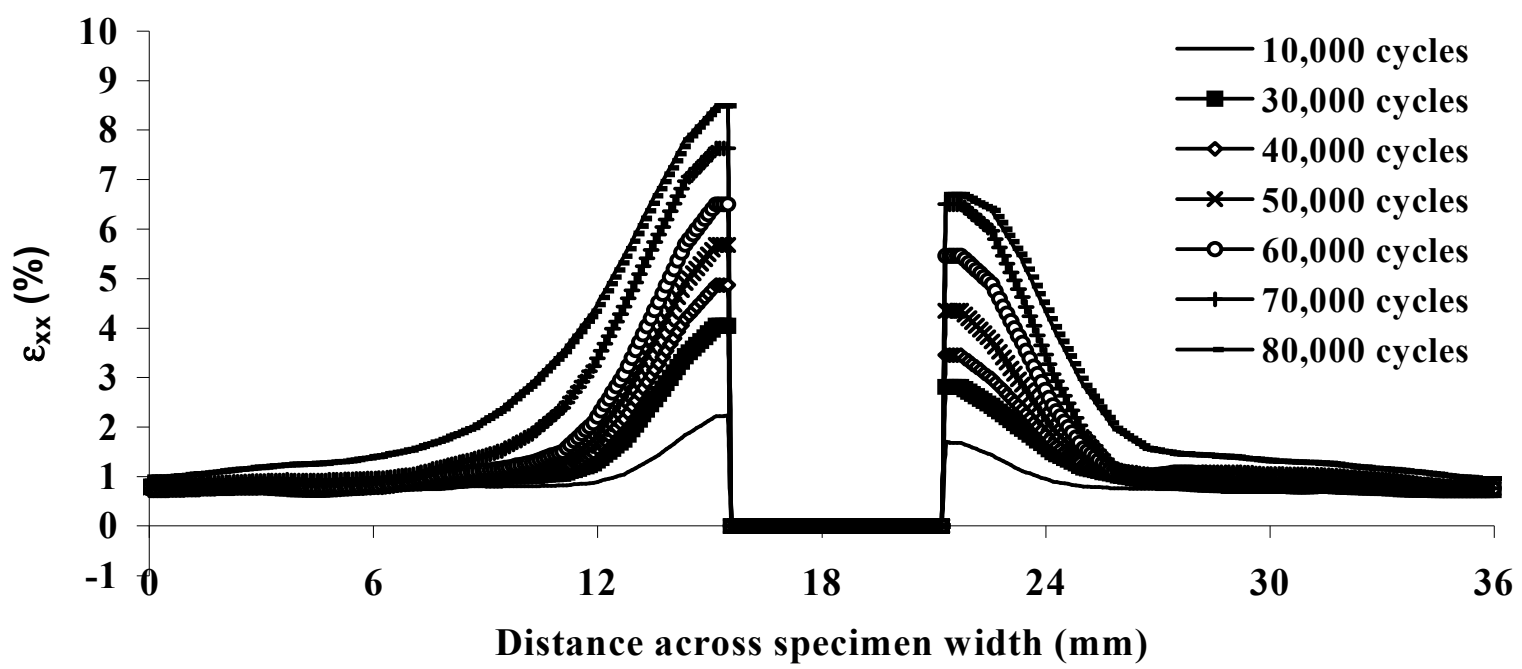

Figure 9. $\varepsilon_{\mathrm{xx}}$ strain distribution around the hole of OHT specimen as a function of loading cycles 
The DIC images shown in Fig. 8 indicate damage growth increases around the hole with increasing number of loading cycles $(\mathrm{N})$. Damage growth is difficult to detect both visually and using non-destructive evaluation methods, such as ultrasonic C-scan and X-radiography. Pulse thermography can be used to monitor damage growth, but the images, although informative, are not as easy to interpret compared with those images produced using DIC. Strain maps of $\varepsilon_{x x}, \varepsilon_{y y}$ and $\varepsilon_{x y}$ when used in combination provide a full picture of the effect of the different damage mechanisms on the in-plane surface strains. The maximum value of $\varepsilon_{\mathrm{xx}}$ strain was taken as the average of the two peak strains either side of the hole (see Fig. 9). This was carried out to account for non-symmetric damage formation around the hole. These averaged peak strains increase linearly with loading cycles (see Fig. 10). Global stiffness is less sensitive to damage growth with dramatic reduction in stiffness occurring near the onset of failure (i.e. last 1-2\% of fatigue life).

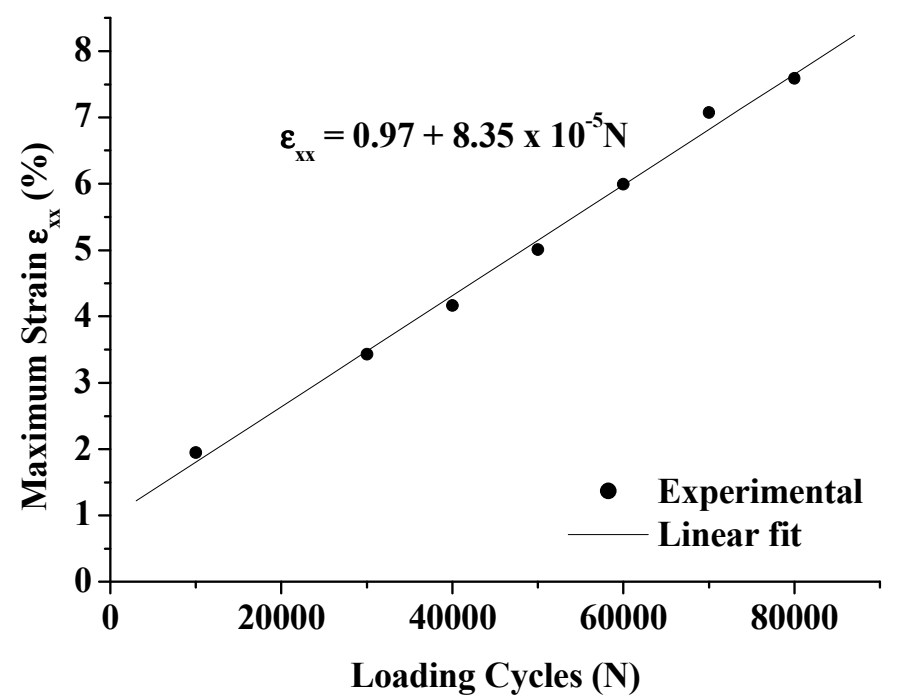

Figure 10. Average peak $\varepsilon_{\mathrm{xx}}$ strain at the hole-edge as a function of loading cycles for OHT

\section{Conclusions}

DIC proved successful in monitoring local and global strains, providing critical information on the changes in strain distribution around the hole of the notched laminates resulting from damage formation and growth incurred through either increasing load or number of loading cycles.

\section{Acknowledgements}

The authors acknowledge the financial support provided by United Kingdom Department for Business, Innovation and Skills (National Measurement Office), as part of the Materials 2007 Programme. The authors would also like to thank Hexcel Composites Limited, and Dr F Surre and Dr T Venugopalan at City University London for their technical support and advice.

\section{References}

[1] B. Wattrisse, A. Chrysochoos, J-M. Muracciole and M. Némoz-Gaillard: Exp. Mech. Vol. 41(1) (2001), p. 29.

[2] J.D. Lord, D. Penn and P. Whitehead: App. Mech. Mater. Vols. 13-14 (2008), p. 65.

[3] F. Lagattu, J. Brillaud and M-C. Lafarie-Frenot: Mater. Charact. Vol. 53(1) (2004), p. 17.

[4] J.M. Whitney and R.J. Nuismer, in: Fracture Mechanics of Composites, ASTM STP 593 (1975), p. 117.

C Crown copyright 2010 